\title{
Olanzapine: A New Atypical Antipsychotic Drug
}

Herbert Y. Meltzer, M.D., and H. Christian Fibiger Ph.D.

This issue of Neuropsychopharmacology includes three preclinical studies (Bymaster et al. 1996; Robertson and Fibiger 1996; Stockton and Rasmussen 1996) and the first controlled clinical trial of olanzapine (Beasley et al. 1996), a novel antipsychotic agent, that was found in the latter study to be more effective than placebo, to cause fewer extrapyramidal symptoms (EPS) and greater decreases in total psychopathology and negative symptoms than haloperidol. Overall, its side-effect profile suggests good tolerability. If these clinical results are confirmed by other controlled trials, especially with a wider range of comparator doses, olanzapine could be a valuable addition to the treatment of schizophrenia as well as other psychoses for which neuroleptic drugs are used. Whether it will be an alternative to clozapine in treatment-resistant and neuroleptic-intolerant schizophrenic patients and how it compares with risperidone as a first-line agent remains to be determined.

After years of acceptance of the principle that antipsychotic drug effects were dependent upon blockade of dopamine (DA) $\mathrm{D}_{2}$ receptors and subsequent depolarization inactivation of mesolimbic dopaminergic neurons, other possible mechanisms of antipsychotic drug action are being considered because the antipsychotic activity of clozapine appears to be only partially dependent upon $\mathrm{D}_{2}$-receptor blockade. Indeed, two agents that cause extremely weak $\mathrm{D}_{2}$-receptor blockade in vivo, amperozide and ritanserin, may also be antipsychotic in some schizophrenic patients, albeit not as effective as clozapine or typical neuroleptic drugs. The

From the Department of Psychiatry, University Hospitals of Cleveland, Cleveland, Ohio.

Address correspondence to: Herbert Y. Meltzer, M.D., Department of Psychiatry, University Hospitals of Cleveland, Hanna Pavilion, Room B-68, 2040 Abington Road, Cleveland, OH 44106-5000.

Received July 28, 1995; accepted September 28, 1995. preclinical studies of Stockton and Rasmussen (1996) and Bymaster et al. (1996) present data comparing olanzapine to clozapine, haloperidol, and other antipsychotic drugs on the firing rate of A9 and A10 DA neurons as well as binding profiles for a variety of brain receptors. These data are useful to test current theories about the mechanism of action of antipsychotic drugs and, ultimately, what chemical and physiologic characteristics may be useful to predict the numerous special clinical features of clozapine, including its beneficial effects on negative symptoms, cognition, tardive dyskinesia, and absence of an effect on prolactin secretion and effectiveness in schizophrenic patients resistant to neuroleptic drugs (Meltzer et al. 1992). Because of the exceedingly complex pharmacology of clozapine, identification of other antipsychotic drugs that share specific clinical features with clozapine will, no doubt, be useful in determining the biologic basis of these clinical characteristics.

Available evidence suggests that olanzapine can produce an antipsychotic action at doses that cause significantly fewer EPS than haloperidol and without serum prolactin increases. Risperidone also produces fewer EPS, but this usually requires that the dose not exceed 2 to $6 \mathrm{mg}$ /day; however, it causes robust increases in serum prolactin levels (Mesotten et al. 1989). There is a variety of possible explanations for this difference between olanzapine and risperidone, which is beyond the scope of this editorial. The point here is that the basis for this difference between olanzapine and risperidone with regard to prolactin secretion can be studied empirically. Such studies may provide important insights into mechanisms regulating pituitary and basal ganglia function. Lower doses of risperidone that do not increase serum prolactin levels may be more effective as an antipsychotic in some patients than the relatively high 
doses used in most studies. It is noteworthy that the 2 $\mathrm{mg}$ /day of risperidone was more effective than placebo in a study of schizophrenic patients that included a mixture of neuroleptic-responsive and -resistant patients (Chouinard et al. 1993). Low doses may be more effective in neuroleptic-responsive patients.

Further clinical study with olanzapine is necessary to determine if its apparent ability to decrease negative symptoms is secondary to its effect on positive symptoms, depression, fewer EPS, and so forth, or if it is an effect on primary negative symptoms. It has been argued elsewhere that clozapine has an effect on primary negative symptoms (Meltzer 1995). If olanzapine is also effective in treating primary negative symptoms in schizophrenia, this would open a vital area for research as well as clinical application, because olanzapine does not appear to have an increased risk of agranulocytosis as does clozapine. Were olanzapine to have a markedly reduced risk of tardive dyskinesia as well, possible long-term application in nonpsychotic disorders characterized by withdrawal, anergia, anhedonia, and alogia could be investigated. It will also be of great interest to determine if olanzapine is as useful in neurolepticresistant patients as clozapine and if it has a low potential to cause tardive dyskinesia.

Stockton and Rasmussen (1996) convincingly demonstrate that chronic administration of olanzapine is clozapine-like in decreasing the firing rate of A10, but not A9, DA neurons in chloral hydrate-anesthetized rats. This supports the view that such a selective effect is a marker for antipsychotic drugs that produce fewer EPS (Chiodo and Bunney 1983). It should be noted that the presumed basis for the decrease in the firing of DA neurons, depolarization inactivation (Chiodo and Bunney 1980), has been challenged by Ichikawa and Meltzer (1989) and Mereu et al. (1995) who believe it could be an artifact related to general anesthesia, even if it does have predictive ability. It should also be noted that $5-\mathrm{HT}_{3}$ antagonists such as zatosetron. (Rasmussen et al. 1991) and granisetron (Minabe et al. 1992) also produce selective inactivation of $\mathrm{A} 10$ neurons. However, there is as yet no evidence that $5-\mathrm{HT}_{3}$ antagonists are effective antipsychotics in schizophrenic patients. This suggests this model may, on occasion, produce false positives. Nevertheless, it appears to be of value in identifying antipsychotic drugs with low EPS potential.

Like clozapine, olanzapine has a high affinity for multiple DA, serotonin (5-HT), and muscarinic receptors. Its highest affinities are for the $\mathrm{m}_{1}$ muscarinic and $5-\mathrm{HT}_{2 \mathrm{~A}}$ receptors. This fits well within a model proposed for atypical antipsychotic drugs of a potent $5-\mathrm{HT}_{2 \mathrm{~A}}$ antagonism relative to $D_{2}$ antagonism (Altar et al. 1986; Meltzer et al. 1989). It is not more potent as a $\mathrm{D}_{4}$ antagonist relative to $D_{2}$-antagonist properties, as is clozapine (Van Tol et al. 1991). It is also much weaker than clozapine as an $\alpha_{1}$ and $\alpha_{2}$ antagonist relative to $D_{2}, D_{4}$, or
$5-\mathrm{HT}_{2 \mathrm{~A}}$ antagonism. Thus, olanzapine should be useful in determining the relative importance of $\mathrm{D}_{4}, \alpha_{1}$ and $\alpha_{2}$ antagonism to the clinical profile of clozapine as well as what effects, if any, are dependent on $5-\mathrm{HT}_{2 \mathrm{~A}}$ antagonism and muscarinic antagonism.

Robertson and Fibiger (1996) show that olanzapine has an atypical profile on regional c-fos expression. Specifically, in contrast to neuroleptics with well-established propensities to produce EPS, olanzapine increases c-fos expression more potently in the nucleus accumbens than in the dorsolateral striatum. On the basis of earlier work, this is predictive of antipsychotic actions of olanzapine at doses that produce little, if any, EPS (Robertson et al. 1994). It is noteworthy, however, that although olanzapine meets this criterion for atypicality, it does produce dose-related increases in c-fos expression in the dorsolateral striatum. This differs from clozapine, which fails to have such an effect even at doses of up to $30 \mathrm{mg} / \mathrm{kg}$ (Robertson and Fibiger 1992). Despite its comparable receptor binding profile, these data suggest that unlike clozapine, olanzapine will have a dose-related propensity to produce EPS. If this hypothesis is confirmed by future clinical studies, it will be important to elucidate the receptor mechanism(s) responsible for this functional difference between the two compounds. Similarly, determining the clinical correlates, if any, of the ability of olanzapine, clozapine, and some other putative antipsychotic drugs to increase c-fos expression in the lateral septal nucleus and the medial prefrontal cortex is an important challenge for future research.

In addition to olanzapine, other atypical antipsychotic drugs (define as low EPS relative to antipsychotic potential; Meltzer [1995]) are completing their phase III research. These include Seroquel, sertindole, and ziprasidone. Like clozapine, olanzapine, and risperidone, they, too, are relatively potent $5-\mathrm{HT}_{2 \mathrm{~A}}$ antagonist compared to their $\mathrm{D}_{2}$ affinities. This group of compounds, together with many other 5-HT-DA antagonists in various stages of development, e.g. iloperidone, melperone, Org 5222, zotepine, and so forth, will provide an important test of the $5-\mathrm{HT}_{2 \mathrm{~A}} / \mathrm{D}_{2}$ ratio hypothesis. It should be noted that ratios of in vitro affinities do not necessarily reflect the relative occupancy of $5-\mathrm{HT}_{2 \mathrm{~A}}$ and $\mathrm{D}_{2}$ receptors in vivo, so PET or SPECT studies that elucidate the doseresponse relationship for receptor occupancy in patients with schizophrenia may be needed to fully test the hypothesis. This is particularly important as differences in endogenous release of DA and 5-HT may affect occupancy of $\mathrm{D}_{2}$ and $5-\mathrm{HT}_{2 \mathrm{~A}}$ receptors respectively (Dewey et al. 1995). Furthermore, new agents with selectivity for the $D_{1}, D_{3}$, and $D_{4}$ receptors are approaching clinical testing as antipsychotics. These agents should provide important tests of current theories of antipsychotic action and side-effect mechanisms, especially whether drugs with a high degree of receptor selectivity are superior to drugs with complex profiles in either or both domains. 
If the latter is the case, it will be important to determine what are the most desirable groups of pharmacologic properties and whether they may differ with respect to their ability to ameliorate the different symptom dimensions of schizophrenia (Liddle 1987a,b).

\section{REFERENCES}

Altar CA, Wasley AM, Neale RF, Stone GA (1986): Typical and atypical antipsychotic occupancy of $D_{2}$ and $S_{2}$ receptors: An autoradiographic analysis in rat brain. Brain Res Bull 16:517-525

Beasley CM, Toleson G, Tran P, Satterlee W, Sanger T, Hamilton S, The Olanzapine HGAD Study Group (1996): Olanzapine versus placebo and haloperidol: Acute phase results of the North American double-blind olanzapine trial. Neuropsychopharmacology 14:111-123

Bymaster FP, Calligaro DO, Falcone JF, Marsch RD, Moore NA, Tye NC, Seeman P, Wong DT (1996): Radioreceptor binding profile of the atypical antipsychotic olanzapine. Neuropsychopharmacology 14:87-96

Chiodo LA, Bunney BS (1983): Typical and atypical neuroleptics differential effects of chronic administration of the activity of A9 and A10 midbrain dopaminergic neurons. J Neurosci 3:1607-1619

Chouinard G, Jones B, Remington G, Bloom D, Addington D, MacEwan GW, Labelle A, Beauclair L, Arnott W (1993): A Canadian multicenter placebo-controlled study of fixed doses of risperidone and haloperidol in the treatment of chronic schizophrenic patients. J Clin Psychopharmacol 13:25-40

Dewey SL, Smith GS, Logan J, Alexoff D, Ding Y-S, King P, Pappas N, Brodie JD, Ashby CR, Jr (1995): Serotonergic modulation of striatal dopamine measured with positron emission tomography (PET) and in vivo microdialysis. J Neurosci 15:821-829

Ichikawa J, Meltzer HY (1990): Apomorphine does not reverse basal dopamine release in rat striatum and nucleus accumbens after chronic haloperidol treatment. Brain Res 507:738-742

Liddle PF (1987a): The symptoms of chronic schizophrenia. A re-examination of the positive-negative dichotomy. $\mathrm{Br}$ J Psychiatry 151:145-151
Liddle PF (1987b): Schizophrenic syndromes, cognitive performance, and neurological dysfunction. Psychol Med 17:49-57

Meltzer HY (1995): Clozapine: Is another view valid? (editorial). Am J Psychiatry 152:821-825

Meltzer HY (1992): Treatment of neuroleptic non-responsive schizophrenic patient. Schizophr Bull 18:515-542

Meltzer H, Bastani B, Kwon KY, Ramirez LF, Burnett S, Sharpe J (1989): A prospective study of clozapine in treatment-resistant schizophrenic patients. I. Preliminary report. Psychopharmacology 99:S68-S72

Mereu G, Lilliu V, Vargiu P, Muntoni AL, Diana M, Gessa GL (1994): Failure of chronic haloperidol to induce depolarization inactivation of dopamine neurons in unanesthetized rats. Eur J Pharmacol 264:449-453

Mesotten F, Suy E, Pictquin M, Burton P, Heylen S, Gelders Y (1989): Therapeutic effect and safety of increasing does of risperidone ( $R$ 67 766) in psychotic patients. Psychopharmacology 99:445-449

Minabe Y, Ashby CR, Wang RY (1992): Effects produced by acute and chronic treatment with granisetron alone or in combination with haloperidol on midbrain dopamine neurons. Eur Neuropsychopharmacol 2:127-133

Rasmussen K, Stockton ME, Czachura JF (1991): The 5- $\mathrm{HT}_{3}$ receptor antagonist zatosetron decreases the number of spontaneously active A10 dopamine neurons. Eur J Pharmacol 205:113-116

Robertson GS, Fibiger HC (1996): Effects of olanzapine in regional c-fos expression in rat forebrain. Neuropsychopharmacology 14:105-110

Robertson GS, Fibiger HC (1992): Neuroleptics increase c-fos expression in the forebrain: Contrasting effects of haloperidol and clozapine. Neuroscience 46:315-328

Robertson, GS, Matsumura H, Fibiger HC (1994): Induction patterns of neuroleptic-induced Foslike immunoreactivity as predictors of atypical antipsychotic activity. J Pharmacol Exp Ther 271:1058-1066

Stockton ME, Rasmussen K (1996): Electrophysiological effects of olanzapine, a novel atypical antipsychotic, on A9 and A10 dopamine neurons. Neuropsychopharmacology 14:97-104

Van Tol HHM, Bunzow JR, Guan H-C, Sunahara RK, Seeman P, Niznik HB, Civelli O (1991): Cloning of the gene for a human dopamine $\mathrm{D}_{4}$ receptor with high affinity for the antipsychotic clozapine. Nature 350:610-614 